\title{
MENURUNKAN DERAJAT FLEBITIS AKIBAT TERAPI INTRAVENA PADA ANAK DENGAN KOMPRES ALOE VERA: STUDI PILOT
}

\author{
Oswati Hasanah $^{1 *}$, Riri Novayelinda ${ }^{1}$, Maifera $^{1}$, Isdelni $^{1}$ \\ 1. Program Studi Ilmu Keperawatan Universitas Riau, Pekanbaru 28293, Indonesia \\ *E-mail: unni_08@yahoo.com
}

\begin{abstract}
Abstrak
Terapi intravena merupakan jenis terapi yang banyak diberikan pada pasien anak yang dirawat. Pemasangan intravena dalam waktu yang lama dapat menimbulkan komplikasi pada anak, seperti flebitis. Salah satu tindakan mengatasi flebitis adalah dengan mengompres Aloe vera yang bermanfaat karena memiliki elektrolit dalam konsentrasi rendah sehingga tidak menimbulkan ekstravasasi. Penelitian ini bertujuan untuk mengidentifikasi pengaruh pemberian Aloe vera terhadap derajat flebitis pada anak. Penelitian kuasi eksperimen ini melibatkan 15 anak yang dipilih dengan consecutive sampling. Semua sampel diberikan kompres Aloe vera murni. Derajat flebitis diukur dengan menggunakan skala flebitis Infusion Nurses Society (INS) sebelum dan sesudah dilakukan intervensi. Hasil penelitian ini menemukan bahwa rerata derajat flebitis sebelum perlakuan sebesar 2,60 dengan skor minimum-maksimum 1-5, rerata derajat flebitis sesudah perlakuan menjadi 1,07 dengan skor minimum-maksimum 0-3. Aloe vera efektif menurunkan derajat flebitis pada anak $(\mathrm{p}=0,000)$. Penelitian selanjutnya perlu dilakukan untuk membandingkan efektifitas kompres Aloe vera dengan terapi non farmakologis lainnya.
\end{abstract}

Kata kunci: Aloe vera, flebitis, pasien anak, terapi intravena

\begin{abstract}
Reducing the Grade of Phlebitis due to Intravenous Therapy in Children with Aloe Vera Compress. Intravenous therapy is a type of treatment that is widely provided to hospitalized children. Intravenous application in a long time causes complications in children, such as phlebitis. One of the interventions in handling phlebitis is compressing Aloe vera which is useful because it has electrolyte in low concentration so as not to cause extravasation. This study aims to identify the effect of Aloe vera on the degree of phlebitis in hospitalized children. This quasi-experimental study involved 15 children selected by consecutive sampling. All samples received a pure Aloe vera compress. The grade of phlebitis was measured using the INS phlebitis scale before and after the intervention. This study found that the mean degree of phlebitis before treatment was 2.60 with a minimum-maximum score 1-5, and after treatment, the average grade of phlebitis was 1.07 with a minimum-maximum score 0-3. Aloe vera effectively decreased the degree of phlebitis in children $(p=0.000)$. Further research needs to compare the effectiveness of Aloe vera compresses with other non-pharmacological measurements.
\end{abstract}

Keywords: Aloe vera, intravenous therapy, pediatric, phlebitis

\section{Pendahuluan}

Terapi intravena merupakan jenis terapi yang banyak diberikan pada anak saat dirawat terutama di ruang rawat intensif. Sekitar $80 \%$ pasien anak mendapatkan terapi infus di rumah sakit (Zheng, et al., 2014). Terapi ini bertujuan untuk mengganti cairan yang hilang, koreksi elektrolit, transfusi darah, atau untuk medikasi
(Lavery \& Ingram, 2008; \& Riris \& Kuntarti, 2014).

Pemberian terapi intravena apalagi dalam jangka waktu yang lama dapat menimbulkan komplikasi. Salah satu komplikasi yang paling banyak terjadi adalah flebitis. Flebitis merupakan inflamasi pada tunika intima vena yang disebabkan oleh faktor kimia, mekanis, bakteri, 
dan post infusion yang menimbulkan efek nyeri, eritema, bengkak dan hangat pada bagian penusukan, pembentukan lapisan, dan pengerasan sepanjang vena (Alexander, et al., 2010; Foster, Wallis, Paterson, \& James, 2002; Saini, Agnihotri, Gupta, \& Walia, 2011). Jenis terapi intravena, kualitas kateter intravena dan teknik pemasangan, serta status penyakit merupakan penyebab flebitis (Premji, 2007).

Anak merupakan kelompok umur yang rentan mengalami kejadian flebitis. Data dari salah satu penelitian di rumah sakit anak di Afganistan menunjukkan bahwa 69,9\% anak yang dirawat mengalami flebitis. Risiko flebitis akan meningkat setelah 24 jam pemasangan dan dilaporkan risikonya meningkat di ruang rawat intensif (Premji, 2007). Penelitian yang dilakukan di ruang rawat anak salah satu RS di Jakarta mengidentifikasi jenis terapi intravena sebagai salah satu faktor yang berkontribusi terhadap kejadian flebitis pada anak.

Skala penilaian flebitis yang banyak di pakai untuk penelitian antara lain Visual Infusion Phlebitis (VIP), Infusion Nurses Society (INS), Maddox, Baxter, Lipman atau Dinley. Secara umum penilaian terhadap flebitis pada skala tersebut dilakukan berdasarkan observasi. Skala VIP dan INS merupakan skala yang banyak digunakan tetapi sampai saat ini belum ada skala penilaian flebitis yang memiliki nilai validitas dan reliabilitas sangat baik (RayBarruel, et al., 2014).

Skala INS pertama kali dipublikasikan pada tahun 1998 di Amerika Serikat dan telah mengalami perubahan menjadi beberapa versi. Penilaian flebitis dengan menggunakan skala $0-4$. Pengamatan yang dilakukan meliputi aspek nyeri, warna kulit, kondisi vena dan jenis cairan yang keluar dari luka flebitis. Royal College of Nursing (RCN) telah mengklasifikasikan derajat visual flebitis yaitu derajat 0 (tampak tempat insersi masih sehat), derajat 1 (nyeri atau eritema pada tempat insersi), derajat 2 (terdapat dua dari kriteria klinis yaitu nyeri, eritema, pembengkakan), derajat 3 (semua dari kriteria klinis tampak jelas yaitu nyeri sepanjang kanula, eritema, indurasi), derajat 4 (nyeri sepanjang kanula, eritema, indurasi, venous cord teraba), dan derajat 5 (nyeri sepanjang kanula, eritema, indurasi, venous cord teraba, demam). Skala INS menggunakan indikator klinis, sehingga secara klinispun terlihat perbedaan pada tiap responden, yaitu dilihat dari eritema, ekspresi nyeri, rabaan vena, warna di area flebitis dan kondisi drainase di area tersebut. Adapun data nyeri pada infant didapatkan dengan menggunakan Wong-Baker Faces Pain Rating Scale, yang disebut nyeri jika intensitas sama atau lebih dari satu.

Adanya flebitis akan membatasi akses intravena, akses cairan, obat dan nutrisi pada anak. Selain itu, flebitis juga akan meningkatkan risiko kejadian infeksi dan sepsis karena bakteri akan masuk melalui area flebitis tersebut ke dalam aliran darah. Oleh karena itu, penanganan yang tepat dan cepat untuk mencegah dan mengatasi flebitis sangat diperlukan untuk menurunkan angka morbiditas anak (Nugraini, 2014).

Penatalaksanaan keperawatan untuk mengatasi flebitis ini telah banyak diupayakan seperti menggunakan kompres alkohol 75\%, $\mathrm{MgSO}_{4}$ 33-50\%, dan larutan garam 0,9\%, namun belum ada yang efektif. Beberapa penelitian menunjukkan penanganan flebitis yang menggunakan air hangat dan antibiotik topikal dapat mengurangi kejadian flebitis pada anak (Oktafiani, Nurbaya, \& Hadia, 2013). Beberapa penelitian mencoba untuk menggunakan terapi nonfarmakologis dengan tanaman tradisional, salah satunya Aloe vera atau dikenal sebagai lidah buaya. Ilmuwan Yunani menyebutkan Aloe vera merupakan tanaman mujarab. Tanaman ini memiliki sejarah panjang dalam penggunaannya sebagai anti inflamasi dan luka bakar. Pengaplikasian secara topikal atau eksternal berupa minyak Aloe vera, daun/batang Aloe vera segar, dan jus Aloe vera merupakan pengobatan adjuvant untuk gangguan pada kulit. Penelitian yang dilakukan di China oleh Zhang, et al. (2014) membuktikan bahwa Aloe vera 
bermanfaat untuk pencegahan dan penatalaksanaan flebitis. Penelitian lain juga melaporkan bahwa dengan mengompres Aloe vera dan campuran gliserin dan magnesium sulfat dapat menurunkan derajat flebitis (Suzanna, Souza, \& Malarvizhi, 2014).

Pemakaian Aloe vera memiliki keunggulan, antara lain mudah didapat dan tidak menimbulkan ekstravasasi karena tidak memiliki elektrolit dalam konsentrasi tinggi. Aloe vera mengandung 20 jenis asam amino dan asam salisilat yang bersifat anti inflamasi dan anti bakteri. Kandungan lignin pada Aloe vera memudahkan penetrasi zat-zat tersebut ke dalam kulit. Selain itu, kandungan Aloe vera lebih sedikit menimbulkan efek alergi pada kulit anak yang masih sensitif (Suzanna, Souza, \& Malarvizhi, 2014).

Pemberian Aloe vera dianggap lebih aman diberikan pada anak mengingat Aloe vera tidak mengandung elektrolit yang dapat menimbulkan ekstravasasi pada pembuluh darah (Zheng, et al., 2014). Penelitian awl ini bertujuan untuk mengidentifikasi pengaruh pemberian Aloe vera terhadap derajat flebitis pada anak.

\section{Metode}

Pada penelitian ini rekrutmen responden yang rentang usianya satu bulan hingga 10 tahun dilakukan karena belum ada catatan angka pasti jumlah dan rentang usia anak yang mengalami flebitis di sebuah RS di Kota Pekanbaru, Riau. Pada saat penelitian berlangsung, kejadian flebitis pada anak yang mendapat terapi intravena juga terbatas, sehingga dengan rentang usia yang panjang diharapkan jumlah responden dapat terpenuhi.

Penelitian eksperimen semua pre dan post-test tanpa kontrol ini melibatkan 15 anak yang dipilih menggunakan consecutive sampling, berasal dari ruang intensiv anak, ruang rawat bedah, dan penyakit dalam. Alat pengumpulan data yang digunakan adalah lembar observasi yang berisi skala derajat flebitis menggunakan skala INS, yang dinilai sebelum dan sesudah perlakuan. Pre-test dilakukan pada hari pertama sebelum intervensi, sedangkan post test dilakukan pada hari ke tiga setelah intervensi selesai dilakukan pada hari kedua.

Cara pengumpulan data dimulai dari penetapan sampel. Setelah ditetapkan sampel sesuai dengan kriteria yang telah ditentukan, peneliti meminta izin kepada perawat ruangan dan keluarga untuk dilakukan kompres. Persetujuan dilakukan dengan menandatangani surat pernyataan. Aloe vera yang digunakan adalah Aloe vera murni yakni dengan kandungan $100 \%$ Aloe vera yang disimpan dalam lemari pendingin. Semua responden diberikan kompres Aloe vera yang dipasang setiap 3 (tiga) jam selama total 8 (delapan) jam setiap hari selama 2 (dua) hari dengan menggunakan kassa.

Analisis data dilakukan dengan perangkat lunak komputer. Analisis univariat dilakukan terhadap data jenis kelamin anak dan derajat flebitis pre dan post test. Analisis bivariat dilakukan dengan uji Wilcoxon terhadap data derajat flebitis pre dan post test.

\section{Hasil}

Karakteristik Responden. Karakteristik responden mencakup jenis kelamin dan usia. Responden sebagian besar berjenis kelamin laki-laki $(66,7 \%)$ dan paling banyak berada pada rentang anak usia sekolah $(60 \%)$. Secara rinci dapat dilihat pada tabel 1 .

Derajat Flebitis. Sebelum Perlakuan Aloe vera sebagian besar derajat flebitis responden berada pada derajat $2(53,3 \%)$. Setelah mendapat kompres Aloe vera, sebagian besar responden derajat flebitisnya berada pada derajat $1(46,7 \%)$.

\footnotetext{
Pengaruh Pemberian Kompres Aloe vera pada Rerata Derajat Flebitis. Tabel 3 menunjukkan rerata derajat flebitis sebelum perlakuan Aloe vera yaitu sebesar $(2,60)$ dengan skor minimum-maksimum (1-5), terjadi penurunan rerata derajat flebitis sesudah perlakuan
} 
Aloe vera menjadi $(1,07)$ dengan skor minimummaksimum (0-3). Hasil analisis lebih lanjut diperoleh $\mathrm{p}=0,000(\mathrm{p}<\alpha=0,05)$ dan dapat disimpulkan bahwa Aloe vera efektif menurunkan derajat flebitis pada anak.

\section{Pembahasan}

Anak yang dirawat di RS sebagian besar akan mendapatkan prosedur medis, baik yang bertujuan diagnostik maupun terapi, diantaranya adalah terapi intravena (Zheng, et al., 2014). McCarthy, Kleiber, Hanrahan, Zimmerman, Westhus, dan Allen (2010a) menemukan tingkat kortisol yang tinggi pada anak yang akan dipasang selang intravena. Hal ini berarti anak mengalami distress. Distress yang dialami anak diantaranya adalah berbagai tingkat cemas, takut, dan nyeri, serta rentang perilaku anak dari yang kalem dan terkontrol sampai panik dan memukul-mukul. Kondisi ini dipengaruhi oleh beberapa faktor, yaitu usia anak, jenis kelamin, pengalaman, tempramen, kecemasan, gaya koping, sensitivitas nyeri, dan genotype, serta persiapan sebelum prosedur. Anak yang lebih muda menunjukkan perilaku distress lebih tinggi dan mengalai nyeri lebih parah akibat prosedur medis (McCarthy, et al., 2010b). Pada penelitian ini tidak dianalisis keterkaitan antara terapi intravena dan karakteristik responden.

Tabel 1. Karakteristik Responden

\begin{tabular}{lcc}
\hline \multicolumn{1}{c}{ Karakteristik } & $\mathrm{N}(15)$ & $\%$ \\
\hline Jenis Kelamin & & 66,7 \\
$\quad$ Laki-Laki & 10 & 33,3 \\
Perempuan & 5 & 40 \\
Umur & & 0 \\
Infant (1 - 12 bulan) & 6 & 0 \\
Toddler (1-3 tahun) & 0 & 60 \\
Pra sekolah (3-5 tahun) & 0 & 9 \\
Sekolah (6-12 tahun) & 9 & \\
\hline
\end{tabular}

Tabel 2. Distribusi Frekuensi Derajat Flebitis Sebelum dan Sesudah Perlakuan

\begin{tabular}{lcccc}
\hline & \multicolumn{3}{c}{ Derajat Flebitis } & \multicolumn{2}{c}{ Sesudah Perlakuan } \\
\cline { 2 - 5 } Derajat Flebitis & \multicolumn{2}{c}{ Sebelum Perlakuan } & $\mathrm{n}$ & $\%$ \\
\cline { 2 - 5 } & $\mathrm{n}$ & 0 & 4 & 26,7 \\
Derajat 0 & 0 & 6,7 & 7 & 46,7 \\
Derajat 1 & 1 & 53,3 & 3 & 20 \\
Derajat 2 & 8 & 20,0 & 1 & 6,7 \\
Derajat 3 & 3 & 13,3 & 0 & 0 \\
Derajat 4 & 2 & 6,7 & 0 & 0 \\
Derajat 5 & 1 & 100 & 15 & 100 \\
Jumlah & 15 & & & \\
\hline
\end{tabular}

Tabel 3. Perbandingan Derajat Flebitis Sebelum dan Sesudah Perlakuan

\begin{tabular}{lcccc}
\hline \multicolumn{1}{c}{ Derajat Flebitis } & $\mathrm{n}$ & Rerata & Min-Maks & $\mathrm{p}$ \\
\hline Sebelum perlakuan & 15 & 2,60 & $1-5$ & 0,000 \\
Sesudah perlakuan & 15 & 1,07 & $0-3$ & \\
\hline
\end{tabular}



Pasien anak yang dirawat dengan pemberian tindakan terapi intravena berisiko mengalami flebitis. Jacinto, Avelar, Wilson, dan Pedreira (2014) menemukan bahwa dari 338 anak, 2,7\% diantaranya mengalami flebitis. Tidak ada kaitan antara karakteristik demografi dengan kejadian flebitis. Pemasangan lebih dari lima hari, perawatan intermiten dan pemasangan terapi yang permanen merupakan risiko flebitis. Selain itu, gerakan aktif anak dan fiksasi yang tidak tepat juga dapat menimbulkan efek mekanik yaitu gesekan kanula ke pembuluh darah dan akhirnya menimbulkan inflamasi pada tunika intima vena (Peach, 2005).

Pada penelitian ini ditemukan sebagian besar anak mengalami flebitis derajat $2(53,3 \%)$ sebelum perlakuan. Setelah mendapat kompres Aloe vera, sebagian besar responden derajat flebitisnya berada pada derajat $1(46,7 \%)$. Derajat 1 artinya terdapat nyeri atau eritema pada tempat insersi, sedangkan, derajat 2 artinya terdapat dua dari kriteria klinis yaitu nyeri, eritema, dan pembengkakan (Higginson, 2011). Hasil ini mendukung hasil studi sebelumnya yang dilakukan oleh Abdul-Hak dan Barros (2014) di Brazil. Mereka melaporkan bahwa pada pasien dewasa yang dilakukan terapi intravena yang mengalami flebitis derajat 1 sebanyak $46,2 \%$, kemudian derajat $2(40 \%)$, derajat 3 $(18,3 \%)$ dan tidak ditemukan pasien yang mengalami flebitis derjat 4. Pada pasien anak di RS di India ditemukan insiden flebitis sebanyak $71,25 \%$ dan mayoritas merupakan flebitis derajat $2(46,25 \%)$ (Nagpal, Khera, \& Kumar, 2015).

Penatalaksanaan flebitis yang selama ini digunakan berupa kompres air hangat, $\mathrm{MgSO} 4$, larutan garam $(\mathrm{NaCl})$ 0,9\%, dan alkohol $75 \%$. Penggunaan beberapa bahan ini belum menimbulkan efek yang signifikan terhadap pengurangan gejala flebitis. Kompres Aloe vera adalah salah satu alternatif penatalaksanaan flebitis yang telah diterapkan pada pasien dewasa di China dan terbukti lebih efektif. Penelitian ini juga menerapkan kompres Aloe vera namun pada anak usia infant sampai usia sekolah yang mengalami flebitis di ruang perawatan.

Berdasarkan uji statistik pemberian kompres Aloe vera murni pada penelitian ini menghasilkan perbaikan yang signifikan berupa penurunan derajat flebitis dengan derajat minimum yaitu 0 dan maksimum 3 . Nilai $p=0,00$ yang dimaknai sebagai terdapat pengaruh Aloe vera terhadap penurunan derajat flebitis pada anak. Hal ini sejalan dengan penelitian Zheng, et al., (2014) yang menjelaskanbahwa Aloe vera mampu menurunkan derajat flebitis dan apabila dibandingkan dengan $\mathrm{MgSO} 433 \%$ atau 50\%, Aloe vera 1,24 kali lebih efektif untuk mengatasi flebitis. Flebitis dapat disebabkan oleh cedera pada vena saat insersi kanula, infeksi, dan iritasi dari zat kimia/medikasi (Alexander, et al., 2010). Iritasi vena dari medikasi maupun cairan infus dipengaruhi oleh faktor $\mathrm{pH}$ dan osmolaritas dari cairan tersebut yang memiliki efek signifikan terhadap kejadian flebitis (Kohno, et al., 2009). Potential of Hydrogen (pH) darah normal berada pada rentang 7,35-7,45 dan cenderung basa sementara cairan yang diperlukan dalam pemberian terapi adalah 7. Antibiotik memiliki $\mathrm{pH}$ yang rendah sehingga berpengaruh terhadap peningkatkan kejadian flebitis. Larutan nutrisi parenteral seperti glukosa, asam amino, dan lipid juga mampu mengakibatkan hal yang sama (Macklin, 2003). Cairan dengan osmolaritas tinggi (hipertonik) juga terbukti lebih sering menimbulkan kejadian flebitis dibandingkan dengan cairan yang bersifat isotonik. Namun cairan isotonik dapat menjadi hipertonik apabila ditambahkan dengan obat, elektrolit, atau cairan nutrisi. Tunika intima pada pembuluh darah vena akan mengalami trauma jika mendapatkan cairan dengan osmolaritas tinggi (Uslusoy \& Mete, 2008).

Aloe vera mengandung 75 zat kandungan aktif seperti vitamin, enzim, lignin, gula, saponins, asam salisilat, asam amino yang beberapa diantaranya memiliki reaksi farmakologis (Shelton, 1991 dalam Zheng, et al., 2014), serta mengandung metabolit sekunder yakni aloe emodin dan chrysophanol (Lee, et al., 2013). Zat-zat ini 
berperan sebagai efek sistem imun, zat pelembab, anti-aging, dan anti-septik. Selain itu, Aloe vera mengandung carboxypeptidase yang menghambat aktivasi bradykinin, salisilat yang juga menghambat proses vasokontriksi (Klein, 1998 dalam Zheng, et al., 2014). C-glucosyl chromone, salah satu kandungan Aloe vera, merupakan anti inflamasi. Kandungan zat ini mampu menurunkan proses inflamasi yang terjadi dengan cara menghambat pengeluaran cyclooxygenase dan menekan produksi prostaglandin E2 (Malik \& Zarnigar, 2013). Penurunan proses inflamasi yang terjadi dibuktikan dengan berkurangnya rerata derajat flebitis sebelum perlakuan yakni derajat 3 yang ditandai dengan nyeri sepanjang kanula, eritema, dan indurasi menjadi derajat 1 yang ditandai dengan tidak ditemukan kembali indurasi dan nyeri atau eritema.

Aloe vera terbukti efektif dan bermanfaat dalam penanganan flebitis pada anak. Pembuatan sari Aloe vera murni relatif mudah dilakukan, dibuat dengan menggunakan bahan-bahan yang sederhana dan diolah dengan cara yang sederhana pula, selain itu juga minimal efek samping. Dilihat dari sudut pandang ekonomis, intervensi ini cost effective dan cost eficient untuk diterapkan di rumah sakit. Akan tetapi, secara metodologis penelitian ini memiliki keterbatasan dalam hal besar sampel. Keterbatasan jumlah sampel menyulitkan hasil ini dapat digeneralisasi. Penelitian ini juga tidak mempertimbangkan faktor atau variabel lain yang mungkin memengaruhi derajat flebitis.

\section{Kesimpulan}

Berdasarkan hasil penelitian ini dapat disimpulkan bahwa sebagian besar responden berjenis kelamin laki-laki $(66,7 \%)$, sebelum intervensi sebagian besar responden dengan derajat flebitis pada derajat $2(53,3 \%)$, sesudah intervensi sebagian besar responden dengan derajat flebitis berada pada derajat $1(46,7 \%)$. Hasil analisis lebih lanjut menunjukkann bahwa Aloe vera efektif menurunkan derajat flebitis pada anak.
Pada penelitian selanjutnya direkomendasikan untuk membandingkan efektifitas kompres Aloe vera dengan terapi non farmakologis lainnya. Disarankan juga untuk menambah jumlah responden agar hasilnya dapat digeneralisasi dengan menggunakan metode uji klinis (LL, NN, INR).

\section{Referensi}

Abdul-Hak, C.K., \& Barros, Â.F. (2014). The incidence of phlebitis in a Medical Clinical Unit. Texto \& Contexto - Enfermagem, 23 (3), 633-638. https://dx.doi.org/10.1590/0104-070 72014000900013.

Alexander, M., Corrigan, A., Gorskin, L., Hankins, J., \& Perucca, R. (2010). Infusion nursing: An evidence based approach. Missouri: Saunder Elsevier.

Foster, L., Wallis, M., Paterson, B., \& James, H. (2002). A descriptive study of peripheral intravenous catheters in patients admitted to a pediatric unit in one Australian hospital. Journal of Infusion Nursing, 25 (3), 159-167.

Higginson, R. (2011). Phlebitis: Treatment, care and prevention. Nursing Times, 107 (36), 1821.

Jacinto, A.K.L., Avelar, A.F.M., Wilson, A.M.M. M., \& Pedreira, M.L.G. (2014). Phlebitis associated with peripheral intravenous catheters in children: Study of predisposing factors. Escola Anna Nery, 18 (2), 220-226. https://dx.doi.org/10.5935/14148145.20140032

Kohno, E., Murase, S., Matsuyama, K., \& Okamura, N. (2009). Effect of corticosteroids on flebitis induced by intravenous infusion of antineoplastic agents in rabbits. International Journal of Medical Sciences, 6 (4), 218-223. doi: 10.7150/ijms.6.218.

Lavery, I., \& Ingram, P. (2008). Safe practice in intravenous medicines administration. Nursing Standard, 22 (46), 44-47. doi: 10.7748/ns 2008.07.22.46.44.c6600 
Lee, Y.S., Ju, H.K., Kim, Y.J., Lim, T.G., Uddin, M.R., Kim, Y.B., ... \& Park, S.U. (2013). Enhancement of anti-inflammatory activity of Aloe vera adventitious root extracts through the alteration of primary and secondary metabolites via salicylic acid elicitation. PloS One, 8 (12), e82479.

Macklin, D. (2003). Phlebitis, a painful complication of peripheral IV catheterization that may be prevented. American Journal of Nursing, 103 (2), 55-60.

Malik, I. \& Zarnigar, H.N. (2013). Aloe vera: A review of its clinical effectiveness. International Research Journal of Pharmacy, 4(8), 75-79.

McCarthy, A.M., Kleiber, C., Hanrahan, K., Zimmerman, M. B., Westhus, N., \& Allen, S. (2010a). Impact of parent-provided distraction on child responses to an IV insertion. Children's Health Care: Journal of the Association for the Care of Children's Health, 39 (2), 125-141. http://doi.org/10. 1080/027 39611003679915

McCarthy, A.M., Kleiber, C., Hanrahan, K., Zimmerman, M. B., Westhus, N., \& Allen, S. (2010b). Factors Explaining Children's Responses to Intravenous Needle Insertions. Nursing Research, 59 (6), 407-416. http://doi.org/10.1097/NNR.0b013e3181f80 ed5

Nagpal, P., Khera, G. K., \& Kumar, Y. (2015). A study assesses the clinical pattern of phlebitis among children admitted in selected hospital of Ambala, Haryana. Nursing and Midwifery Research Journal, 11 (2), 68-77.

Nugraini, Y.C. (2014). Analisis faktor-faktor yang berhubungan dengan kejadian plebitis pada pasien anak di ruang Pinus Eka Hospital $B S D$ (Skripsi, Tidak dipublikasi). Universitas Esa Unggul. Diperoleh dari http://digilib. esaunggul.ac.id/analisis-faktorfaktor-yangberhubungandengan-kejadian-pl ebitis-padapasien-anakdi-ruang-pinus-eka-hospitalbsd skripsi-2458.ht ml.
Oktafiani, N., Nurbaya, S., \& Hadia (2013). Pengaruh pemberian kompres air hangat dan terapi antibiotik terhadap penyembuhan phelebitis di Ruang Perawatan Anak RSUD Daya Makassar. Diperoleh dari http://library. stikesnh.ac.id/files/disk1/4/e-library\%20stik es\%20nani\%20hasanuddin--ninaoktafi-1801-ar tikel-3.pdf

Pearch, J. (2005). Restraining children for clinical procedures: In contrast to staff in educational settings, child health professionals are not receiving adequate training for holding and restraining children. Jo Pearch explores the issues. Paediatric Nursing, 17 (9), 36-38. http://dx.doi.org/10.7748/paed.17.9.36.s27

Premji, R. (2007). French Medical Institute for Children (FMIC): A study on incidences of phlebitis and causes in pediatric patients at FMIC, Afghanistan. Diperoleh dari http:// www.stti.iupui.edu/pp07/congress10/premji _r.pdf

Ray-Barruel, G., Polit, D.F., Murfield, J.E. \& Rikard, C.M. (2014). Infussion phlebitis assessment measures: A systematic review. Journal of Evaluation in clinical practice. 20 (2), 191-202. doi: 10.1111/jep.12107.

Riris, E., \& Kuntarti. (2014). Pengetahuan tentang terapi intravena berhubungan dengan perilaku perawat dalam pencegahan flebitis. Jurnal Keperawatan Indonesia, 17 (3), 108118. http://dx.doi.org/10.7454/jki.v17i3.456

Saini, R., Agnihotri, M., Gupta, A., \& Walia, I (2011). Epidemiology of infiltration and phlebitis. Nursing and Midwifery Research Journal, 7(1). Diperoleh dari http://medind. nic.in/nad/t11/i1/nadt11i1p22.pdf

Suzanna. J.D., D' Souuza. S.W., \& Malarvizhi. M (2014). Effectiveness of fresh aloe vera and glycerine magnesium sulphate: Application on phlebitis among children. Internationa Journal of Current Research. Diperoleh dari http://www.journalcra.com/sites/default/files 15659_0.pdf 
Uslusoy, E., \& Mete, S. (2008). Predisposing factors to phlebitis in patients with peripheral intravenous catheter: A descriptive study. Journal of the American Academy of Nurse Practitioners, 20 (4), 172-180. doi: 10.1111 jj.1745-7599.2008.00305.x.
Zheng, G. H., Yang, L., Chen, H. Y., Chu, J. F., \& Mei, L. (2014). Aloe vera for prevention and treatment of infusion phlebitis. Cochrane Database Syst Rev (6), Cd009162. doi: 10.1002/14651858.CD009162.pub2. 